\title{
IS AFRICAN SCIENCE TRUE SCIENCE? REFLECTIONS ON THE METHODS OF AFRICAN SCIENCE \\ DOI: http://dx.doi.org/10.4314/ft.v5i1.5
}

\author{
Oseni Taiwo AFISI, Ph.D \\ Department of Philosophy, Lagos State University, Ojo, Lagos, Nigeria
}

\begin{abstract}
The general character of science and the methodology it employs are in specific terms referred to as observation and experimentation. These two methodologies reflect how science differs from other systematic modes of inquiries. This description characterises, strictly, 'Western science' and it is contrasted with the indigenous mode of enquiry that has come under the name, 'African science'. In contemporary scholarship, 'African science' is being condemned to the level of the mysticoreligious or supernaturalist worldview. 'African science' is said to be purely esoteric, personal, and devoid of elements of objectivity and rigorous theorization. In this paper, I re-examine this recondite issue by further reflecting and strengthening some of the ideas put forward by some African scholars to affirm that there is a distinct method of 'African science' that can be termed scientific. In defending a pluralist thesis toward knowledge, scientific inclusive, this paper posits that there exist varieties of inquiry beyond what has been developed in the 'West' which can still be justifiably termed scientific. In addition to pluralism, it argues further that the social character of science, which makes it a part of social and cultural traditions, qualifiedly justifies 'African science' as a true science. I will employ the newly formulated conversational method endorsed by the Conversational School of Philosophy (CSP) in this inquiry.
\end{abstract}

Keywords: African science, mystico-religious, rigorous, pluralism, Western science

\section{Introduction}

In his book, [Consilience], E.O. Wilson describes the nature of science as "the organized, systematic enterprise that gathers knowledge about the world and condenses the knowledge into testable laws and principles" (WILSON 1998, 58). This view sees science as the concerted human effort to have a clear understanding of the history of the natural world and how the natural world works, with observable physical evidence as the basis of that understanding. This description represents the general character and nature of science, as well as what can be termed scientific in a broad sense.

If what the scientist does is to understand the cosmos through observable oevidences in order to proffer appropriate technical and rational solution to it, then this $\boldsymbol{D}_{\text {is }}$ an approach that can be significantly found in every rational and intellectually open society. Such an explanation simply bourgeons into a pluralism in science that 
extinguishes the idea of a single self-consistent mode of rationality that could be universalized. A universalism of science would deny the impressiveness of plurality in science.

The point being stressed is that an attempt at globalizing science, in particular, through the viewpoint of Western science would impress upon other nonWestern societies the particular yardstick for measuring what is scientific. Such an attempt would obscure the need to recognize that there exists other systematic indigenous approaches to science, different from Western science that maintain significant indigenous methods of inquiry of their own. The accomplishments that different cultures all over the world have attained in the thousands of years that people have lived in various societies only confirm that systematic indigenous knowledge is wrapped around rational inquiries about the natural world.

The criteria for what passes as the standard of rational inquiry in Western science cannot be used as a parameter of what can pass muster as knowledge in other cultures, as experiences, values, history and politics differ from one culture to the other. The values and potentials of pluralistic paradigm of science is that it takes into account local knowledge and practices of a particular environment and its people with a view to distilling systematic indigenous knowledge and its methodologies.

It is this motivation which underlies the works of some African scholars such as Chris Akpan, Jonathan Chimakonam as well as Christian Emedolu on the structure and methods of African science. Their ideas draw support from more recent works in African thought, particularly from the works of Ivan Van Sertima's [Blacks in Science: Ancient and Modern] (1984) which details examples of scholars' accounts on African science, and on the countless number of contributions that African civilizations have made to science on the continent and beyond. Akpan, Chimakonam and Emedolu respectively buttress the argument that there is no one universal method of doing science; and that every science esteems the idea that knowledge is part of social and cultural traditions. As such, scientific ideas are developed, advanced and affected by socio-cultural and historical orientations.

Akpan categorized African science into two classes: traditional African science and modernized African science. As with their counterparts in the West, traditional African scientists, according to Akpan, are interested in the inquiry about understanding the nature of reality. However, unlike Western science which distinctly separates science from technology as independent fields of human endeavor, traditional African science stands out in its ability to combine the inquiries into the nature of the cosmos with the application of such knowledge into technicalities. African traditional scientists are regarded as scientists and technologists at the same time (AKPAN 2010, 15).

For Akpan, the modernized African scientist uses a hybrid of traditional African scientific method and the method of modern Western science. "The Emodernized African scientist incorporates the techniques of Western science, like

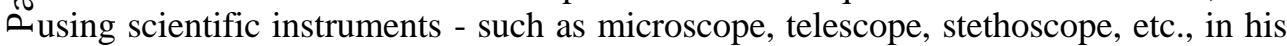
experimentations. He may even have traditional laboratories, the products may be 
standardized" (AKPAN 2010, 17). Some modernized African scientists, in spite of their formal training, still employ some aspects of traditional African culture when engaging in their activities (AKPAN 2010, 17).

Similarly, Chimakonam puts forward an approach which is aimed at a systematisation of African science. This systematisation is a rigorous consideration of the various transition that the methods of African science have continued to witness. Chimakonam enumerates five methods that capture African science beyond Akpan's descriptive level, to the level of systematisation and experimental science. These methods include, according to him, "Ako-nwalee" (Trial and error), "Ako-ijuase" (Interscience), "Ako-ime-obi" (Introscience), "Ako-nyirionwe" (Semscience), and "Ako-nso-n' azu" (causal science) (CHIMAKONAM 2012a, pp.36-39).

Emedolu's attempt to forge a new paradigm in African experimental science consolidates on the systematisation approach of Chimakonam. Emedolu's supposition is that African experimental science must be relishable on the inherent natural magical tradition that pervades the culture of the people of the continent. His reason is simply because "European science itself emerged out of its own magical tradition" (EMEDOLU 2015, 83).

Consequent upon the above categorizations, central to this paper is the issue of whether there exists a method(s) of African science that can truly be termed scientific. This paper focuses on discussing only issues concerning the method(s) of traditional African science. It is aimed at establishing the thesis that every systematic indigenous knowledge or scientific inquiry reflects cultural differences. My outlook in this paper will seem controvertible in the eyes of many who believe that cultural differences cannot be determinative of good science. My argument is that there is a socio-cultural character to the development of science. This is to the extent that the methods of inquiry in science, and the views that its practitioners will adopt concerning their subject matter, are significantly a function of culture and of a cultural history that will be unique to a time and a place.

In this essay, I will engage with some African scholars on the reality of African science, its methods and justifications in order to open new vistas of thought on the subject as suggested above. This is one of the key goals of conversational mode of inquiry newly formulated by Chimakonam (See CHIMAKONAM 2015, $2015^{\mathrm{b}}, 2015^{\mathrm{c}}$ ) and promoted by the Conversational School in African philosophy (See NWEKE 2015; EDET 2015). In sum, conversational philosophy or thinking or the method of conversationalism is a procedure that is interested in continuous questions and answers that lead to revision of ideas. As Chimakonam puts it:

By conversational philosophy we mean a rigorous and critical philosophical engagement between individual thinkers with one another on phenomenological issues of concern or on one another's thoughts where the opponent contests and the proponent defends the viability of such thoughts. In African philosophy, conversational philosophy may prioritise the issues concerning Africa. On the whole, it is a rigorous intellectual encounter between two sides called 
conversationalists; the one called $n w a-n j u$ or the inquirer who poses critical and confrontational questions to the other on the other's thoughts; and nwa-nsa or the responder who attempts to answer such questions either posed to him or to another or to all. $\left(2015^{\mathrm{c}}, 463\right)$

I suppose therefore that in following this method of inquiry in this paper, I will be the nwa-nju while the various scholars I shall engage will be the nwa-nsa. In the end, my goal will be to attempt to open new vistas of thought on the subject of African science.

\section{The Nature and Methodology of science}

Philosophers of science in the Western philosophical tradition, such as the logical positivists of the Vienna Circle as well as Karl Popper have theorized about the nature of scientific methodology. The logical positivists had earlier used the verification principle to demarcate science from non-science. They sought to explain the difference between science and non-science by reference to the idea that science alone is meaningful, that meaningfulness consists in verifiability, and that science is steadfast in its orientation to empirical verification (Popper 1959, 11).

In contrast to the logical positivists Popper emphasized the negative idea of falsification as hallmark of scientific thinking. Popper believed that the logical positivists were mistaken when they conflated two quite different philosophical problems, the problem of meaning and the problem of demarcation. They had used their verification principle as a solution to both the problem of meaning and the problem of demarcation (AFISI 2013, 507). For Popper, falsificationism is the thesis that a hypothesis can be termed scientific only if it has the potential to be refuted. A theory is scientific only if it is falsifiable. Popper thus used falsification as a criterion for demarcation to distinguish the true scientific attitude from the unscientific. The true scientific attitude, according to Popper, is witnessed in Newton's theory of gravitation as well as Einstein's theories of relativity. In Popper's view, this true scientific attitude differs from what Marxists have toward their "Marxism, or by Freudians toward their psychoanalysis, or by Adler towards his individual psychology, for by their attitude these various thinkers render what they espouse immune from potential falsification" (POPPER 1963, 44). They are dogmatic rather than critical, so what they offer is mere pseudo-science.

Clearly, a typical Western philosophical tradition would denounce any viable methodology for science with embedded metaphysics. In fact, the logical positivists had used their "verificationist" criterion of meaningfulness chiefly to attack metaphysics as meaningless in acquiring any kind of knowledge. Although NPopper regards metaphysics as uncritical which cannot pass in the realm of Ofalsification, he does not regard it as meaningless. Metaphysics is pseudoscience, but od may have significant relevance to the growth of science. Popper held that even $\approx$ though falsification is a single specifiable method which can be taken as a procedural criteria for all the sciences, there can be non-scientific, metaphysical inquiry, that 
later emerges as a mode of scientific inquiry. We are not to condemn the metaphysical outlook in science, for that might have been a necessary step to get a new science going (POPPER 1959, 19, 38, 252., BARTLEY 1968A, 47-54., POPPER 1968, 93-98., BARTLEY 1968B, 115, 118)

In consideration of the above two positions, that is, the logical positivists on the one hand, and Popper on the other, the methodology of what it is to do good science rests only on verificationism and falsificationism respectively. Although their procedures differ on the specific road to the progress of science, what is common to both is the agreement that the scientific method of inquiry is based on empirical evidence that is predicated on some specific principles of reasoning.

\section{Is there an African Science?}

Much like the historical and intellectual debate on the existence of African philosophy, the existence of a distinct African science with its specialized method(s) has also been a subject of debate. One of many "denialists" of the existence of African science is Samuel Tunde Bajah (1980). Bajah published a monograph entitled "African Science: Fact or Fiction" wherein he argues against the notion of the existence of an African science. His assertion is that "there is science in Africa but there is no African science" (BAJAH 1980, 25). Contrary to Bajah, a profound assertion on the existence of African science can be found in Brian Murfin's (1992) article entitled, "African Science in School Curriculum". Murfin unequivocally responded that, there is African science; and its existence is what calls for the activities, the nature of understanding and explanations of the phenomena that occur in Africa. So, just as science exists in other parts of the world, there is also African science where efforts are made by traditional thinkers in Africa through their years of training in attempts to unfold the truth in nature (MURFIN 1992). This is further buttressed by Nwankwo Ezeabasili's position that the African has an authentic scientific culture. Accordingly, African science is "African account of nature and how it works" (EZEABASILI 1977, xi). Apparently, this debate on whether there is African science or not continued for some time until Chimakonam $\left(2012^{\mathrm{b}}\right)$ first attempted a broad-based system in African science.

Following from the above, a thesis has been established that there exists a pluralism in science where inquiries are made in every systematic indigenous culture on how to explain the nature of the universe. The methodology that is employed in African science, for instance, is distinctively unique to the cultural orientation of the people. This may change over time as culture evolves. However, if we have to compare the nature and methodology of African science with what exists as the methodology of scientific research in Western science, we may not come to much

Magreement regarding what is truly the acceptable methodology of science. Such Ocomparison would foster certain level of competition as each indigenous system of oninquiry is required to conduct its science through any methodology that suits its

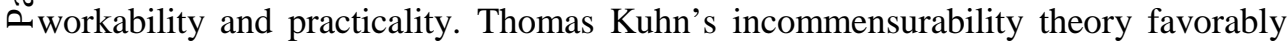
addresses this notion, that competing paradigms often lack a common measure, 
because they use different concepts and methods to address different problems (KUHN 1962, 71). Also, Feyerabend's incommensurability theory supports a pluralism in science which asserts that there exists no single scientific method we could agree to which would ultimately foster criticism or severe testing of theories. For Feyerabend, "the events, procedures and results that constitute the sciences have no common structure" (FEYERABEND 1988, 1).

The incommensurability that both Kuhn and Feyerabend advocate is to emphasize, in this sense, that different philosophical or cultural traditions can acquire the knowledge based system of inquiry indigenous to them and can as well develop or adopt a workable methodological procedure for their scientific research. Incommensurability promotes in a parallel way the requirement of scientific pluralism. It discourages a situation where there exists a globalized scientifically single self-consistent over-arching mode of inquiry. Pluralism embellishes one way or another, scientific methodology to be open, by nuance that is different if the subject matter is different, or if the historical epoch is different, or if the cultural milieu is different, or if different personalities are at work.

Scientific pluralism, therefore, nullifies the idea of a methodological unity in science which holds that there are universal procedures, laws or methods that are defining of science and that consequently are applicable to all fields of scientific inquiry, despite the patent variety in science itself. Scientific pluralism extends this idea to non-Western modes of inquiry. It is within this established thesis of pluralism in science that Chimakonam distinctively points out the fundamental differences between Western science and African science. This is in a bid to establish that each indigenous system of knowledge or inquiry is distinct in nature, features and character; as each one responds to the challenges within its cosmology. According to Chimakonam, "Western science is a body of organized knowledge whose pursuit is tied to the principle of empirical, testable and demonstrable protocol. African science is a body of organized knowledge concerned with enquiries into all shades of reality in African world view supported with rational explanations. The difference is that in the former, scientific enterprise is restricted to a segment of reality namely, the empirical, while in the latter, there is no such restriction" (CHIMAKONAM 2012b, 7). This distinction epitomizes the differences, in particular, the emphasis on empirical, on one hand, and non-empirical/beyond-empirical methodologies, on the other. Western science is restricted to the former, and the latter is employed within the sphere of African science.

\section{Traditional African Science: Nature, Challenges and Strengths}

In his paper, [The Method of African Science: A Philosophical Evaluation] Akpan $\checkmark$ enumerates a number of methods that characterize traditional African science. He Onotes that the methods of observation and experimentation, which are hallmarks of ovevery science or systematic indigenous forms of inquiry also, have a significant place $\widetilde{D}$ in traditional African science. Akpan, however, avers that the level of sophistication 
that observation and experimentation have reached in Western science today is higher than what traditional African science presents (AKPAN 2010, 15).

The above assertion, by Akpan, may be correct if we are able to essentially comprehend the advancements in observation and laboratory experimentations that have come to characterize Western science today. Indeed, the level of scientific innovations and inventions that Western science epitomizes is significantly impressive. There is really no room for comparing the level of achievements and developments between Western science and traditional African science, except for the purposes of a cross-cultural "polylogue". The purpose of this "polylogue" is that when two cultures, for instance, dialogue, ideally people in both cultures learn from their understanding of the other what can be accepted or jettisoned. This would represent the possibilities of mutual benefit if there is intelligent dialogue concerning the differences and the commonalities (AFISI 2012, 104). In this way, while traditional African science may not be as burgeoning as to the same extent as that in the West, it yet maintains significant indigenous methods of inquiry of its own.

Moreover, the gradual pace at which traditional African science can be said to be developing can be looked at from the perspective that the gradual level of development that Western science had to go through right from the Ancient Greek period through to the Renaissance, and to its current form, is indicative of the kind of dialectics that Hegel talked about. At the thesis stage, Western science would be "ancient" in its raw initial form. It moved beyond the stage of anti-thesis to the stage of synthesis. As Hegel noted, development is a becoming and it is non-static. Ultimately, the synthesis becomes a new thesis, and the cycle is a continuum. This is the state of development in science. This is also obtainable in traditional African science. Traditional African science is no longer in its "ancient" thesis stage. The development in trends and methods of traditional African science has evolved significantly over the years to a level of sophistication that can truly be termed scientific. Well documented achievements of African scientists can be found in Sertima's edited book earlier mentioned where African science excels in various disciplines of Western categorisation of science. The various accounts of scholars in Sertima's edited work reveals African science contributions in chemistry; in astronomy on how the Dogon of Mali had an excellent understanding of the solar system; in mathematics, on how the Yorubas had a superbly complex number system based on twenty; in biology; in agricultural crop production; and in medicine and surgery (SERTIMA 1984) .

In furtherance of the thesis that African science exists in order to find solutions to some of the fundamental challenges faced within its cosmology, Chimakonam's three-way justification of the African science project defends this $\Omega$ assertion. First is the need to develop a science that fits with African native thought System. Second is the need to have an environment friendly science as an alternative ogto Western science, which currently presents serious environmental problems. Third $\mathcal{C}_{\text {is }}$ the need for a science that can offer safe and adequate energy to the world (CHIMAKONAM 2012b, 8). These justifications present African science as that 
which arises out of the utmost need to establish an indigenous brand of African logic embedded within the African thought system. It is a science which is eco-friendly and presents itself as capable of providing safe and adequate energy to the people of Africa. Such is a science that its practitioners have shown the capacity for relevance, as African traditional scientists have continued to excel in the various interdisciplinary fields of science, be it, orthopaedic, soil, crop and animal sciences, metrology, astronomy, and medical sciences.

\section{Method of African Science}

Akpan identifies one fundamental method of traditional African science. This is the method of causality with an underlying mythico-religious dimension. In discussing causality as a method of science, Akpan points to the essential role that causality plays in the nature and character of traditional African science. In his general analysis of causality, Akpan first simply makes a sweeping generalization of the role of causality in Western science by stating how the Western scientist strives to give a causal explanation to things within the physical universe (AKPAN 2010, 15). Akpan's intention is to show that causal inevitability of natural phenomena underlies every scientific research.

In making a clear distinction on what makes causality in African science different from what is obtainable in the West, Akpan notes that caution must prevail in not confusing the idea of causal explanations with the idea of causality. He points out that though there are differences in agents of causation, as well as assumptions behind causative patterns, there is no fundamental difference in the idea of causality, whether in the West or in Africa. Causality still simply means "A causes B" in both contexts.

Essentially, Western philosophers of science are not agreeable on the principle of causality as a method of scientific inquiry. Philosophers such as David Hume (1711-1776), for instance, see causality as a defective system of inquiry. Hume argued that the assumption of cause and effect between two events, A and B, say because A causes B, because the two always occur together we can then conclude that A always causes B, are not necessarily true. Causality, to Hume, does not guarantee us how experience can give us adequate knowledge (HUME 1902, 111). It is this deficiency in causality that gave rise to the problem of induction in philosophy of science.

In Hume's criticism of causality a regular succession of events which necessarily follow one another is impossible to know for certain. This assertion is also true of what has been termed the problem of induction. Induction is regarded as the process of inferring a general law or principle from observation of particular instances. A broader construal of induction depicts induction as a process where the premises of an inductive argument indicate some degree of support (inductive approbability) for the conclusion, but do not entail it (VICKERS 2013). This broader

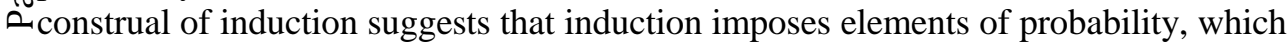
means the certainty of the conclusion is a matter of degree. 
With Hume, the problem of induction surrounds simply 'enumerative induction'. Such ostensible inferences lead from specific observations to a generalization. Poppers, however, used Hume's skepticism concerning induction more creatively, as a basis to dismiss the inference form of 'enumerative induction'. Popper insisted that you need to be able to distinguish between 'good induction' and 'bad induction' in order to point to any induction at all. So if Hume shows that there is no such thing as 'good induction', then the conclusion must be that 'induction' is an empty concept. We need, Popper insisted, a way of thinking about science that is deductivist, rather than inductivist. Popper used hypothetico-deductivist thinking to account for science.

What the above clarification on causality signifies is that Western science does have disagreements on the role that causality places in scientific inquiry. Even for the Western scientists who accept causation in science, causality is usually limited to empirical causation, where questions such as what makes ' $A$ ' to cause ' $B$ ' or how event ' $\mathrm{B}$ ' is possible in the face of ' $\mathrm{A}$ ' are asked (AKPAN 2010, 15). However, to the traditional African scientist, causality helps to understand the logical richness of generalizations in science. It helps to deepen the understanding of the nature and causes of events beyond the causal empirical explanation of which Western science is limited. The Western scientist is interested in explaining the empirical causation involved in event ' $A$ ' causing event ' $B$ '. The specialist traditional African knowledge inquirer is involved with what Kwame Gyekye calls "agentive causation" (GYEKYE 1997, 28). The traditional African scientist is interested in the explanation of the cause of an event, a sickness or death. The scientist will tend to raise the questions "who caused it" and "why it was caused" rather than the "what and how - questions" (AKPAN 2010, 15).

Advancing further from Akpan's classification of the method of African science as "agentive causation", Chimakonam in his [Towards a Theory of African Science: Methods and Justification], attempts a systematisation of African science. Chimakonam's systematisation of five methods in African science is a practical description of the development of traditional experimental science in Africa. These methods include, according to him, "Ako-nwalee" (Trial and error), "Ako-iju-ase" (Interscience), "Ako-ime-obi" (Introscience), "Ako-nyirionwe" (Semscience), and "Ako-nso-n'azu" (causal science) (CHIMAKONAM 2012a, pp.36-39). These methods represent the various experimental traditions that characterise African science. The ("Ako-nwalee") trial and error method articulates how the scientist ventures into designing a project, sometimes without having a clear path to take. The ("Ako-iju-ase") interscience method is an approach in which there is a non-empirical dimension to the forms of experiment carried out by the scientist. The ("Ako-ime(obi") intransience employs a mechanical dimension to scientific inquiry, but it is Omade possible through the functions of the mind. The ("Ako-nyirionwe") orSemscience method of inquiry is inductive in nature. It is characterized by its

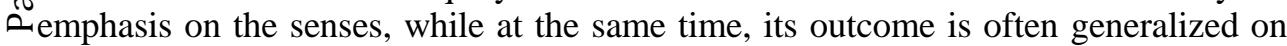
the basis of its individual circumstances. The ("Akọ-nso-n'azụ") causal science 
heightens all the other methods of African science. It embraces the idea of "agentive" causation but moves further to establish a transcendentalist view of causation. This view considers many other factors on the many causes that can as well produce the same effect. So as a method of African science, it ensures that the right cause of things is identified to be able to understand the effect it produces.

So, with the establishment of causality as a pivotal method of African science, its embedded richness of metaphysics becomes essential. Many Western scientists would consider this erroneous, and will inadvertently condemn African science to the level of mysticism, spirituality or religiosity. However, scholars such as, Chimakonam, have defended the metaphysical nature of African science. According to him, "a science which does not include the metaphysical in its map of reality is surely not...African science" (CHIMAKONAM 2012a, 35). Others such as Gyekye, and Jim Unah have affirmed that the richness of metaphysics and ontological categories of causality in traditional African science is validated. So the condemnation of it is misplaced, because it is what gives distinctiveness to the methodology of its science. Both Gyekye and Unah are assertive and categorical about the positive dimensions of these ontological categories of causality; as they are compatible with the story of a harmonious African society. To Unah, the African society is a world where everything interpenetrates, where the physical and spiritual conflate. There exists an extraordinary harmony in African society, one of synthetic unity and compatibility among all things (UNAH 1995, 107). In relation to traditional African science, Gyekye also affirmed that the method of traditional African science has significant mystico- religious undertone because traditional African culture is greatly rich in the idea of causality, which is generally understood in terms of spirits and mystical powers (GYEKYE 1997, 28).

Clearly, such affirmation of a mystic-religious orientation in traditional African science is not a negative idea. Rather, it is a strength for which traditional African science remains distinct in its nature and methodology. It signifies its richness in metaphysics and epistemology as forms of scientific inquiry. This richness embellishes the understanding of a scientific outlook of the world through means beyond empirical causation. So, as a method of inquiry, mystico-religious consciousness is both spiritual and mystical. Although it is much more spiritual and no less literal-minded, the mystico-religious inquiry cannot be said to be the complete antithesis of Western science.

Truly, one can say that in most non-Western scientific traditions thinking resonates with the abstract idea of nous (which sees knowledge as the perception of the mental rather than the physical) that is associated with the mystic philosophy of Plotinus. It can also be reiterated that mysticism or religiosity does not necessarily $\infty_{\text {hinder the progress of knowledge, as Western societies were still largely religious }}$ $\emptyset_{\text {while science progressed there. }}$

So, the embrace of the mystico-religious mode of inquiry that is associated

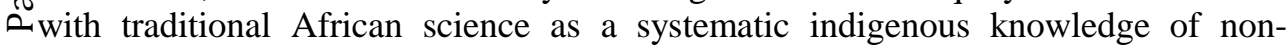
Western orientation, is quite compatible with the claim that the spiritual is incidental 
to the physical. This is to the extent that it is believed that the spiritual affects physical phenomena. As I have observed above, it can categorically be said that religious belief was equally integral to the motivation of much of Western science. Western scientists at some point were trying to understand the mechanisms by which God had constructed the world. The way that the religious motivation played out was tied to the earlier influence of the Greeks, with their literal minded pursuit of rational understanding. However, this claim does not preclude the fact that science was also at some point in conflict with religious views. A case in point is the ideological conflict that occurred of the Copernican heliocentrism with the Galileo affair against the geocentric model of the Catholic Church. Moreover, the relationship between science and religion since classical antiquity has been controversially characterized as either one of conflict or harmony. Nevertheless, a more qualified claim would affirm that despite these differences most scientific innovations before the Copernican revolution in the history of science were achieved by societies organized by religious traditions (AFISI 2016, 64).

In all of these, the point being made is that the notions of metaphysics, mysticism and religiosity which underlie the method of traditional African science point to the fact that those notions are significantly compatible with the culture and history of the people. Granted that Western science have dispatched those notions from the ambience of its methodology, the embrace of a rational justification to objective science is not the signature of Western science alone. There exists no monolithic standard of rationality that can be read out of Western science only. What exists is a pluralistic way of knowing that takes into account both empirical and nonempirical approaches to rationality.

This argument establishes that there are other competing paradigms of rationality aside from what is obtainable in Western science. As such there is no identity problem foisted on what is known as 'African science. This suggests that what is regarded as the standard of scientific rationality is something that is specified in each research tradition and epoch; as such there is no single "logic" of scientific reasoning that could be specified once and for everyone. Chimakonam's "Igbo" adage "Nku di n'mba na eghelu ha ite", meaning, "The firewood found in any nation is what cooks for the natives" (CHIMAKONAM 2012b, 4) buttresses this assertion. What this suggests is that scientific solutions to immediate existential problems require people to look inward for solutions; as problems and solutions are sometime contextualised to one's social environment. Since the environment to a large extent determines the structure of science, African environment like its western counterpart technically, will engender a different science from the point of their ontological and fundamental differences. The indication here is that each one of them would develop technical solutions to the challenges of their peculiar environments (CHIMAKONAM 2012b, 4-5). 


\section{Conclusion: Towards a Viable Non-Empirical but Rigorous Method of African Science}

A nuanced evaluation of the nature of traditional African science that Akpan made reveals that the method of African science has been condemned to be purely superstitious, esoteric, mystically and religiously inclined (AKPAN 2010, 18). This is indeed a one-sided perspective to the general outlook on traditional African science. Akpan affirms that there is an empirical evaluative procedure in traditional African science that compliments the mystico-religious method. This is the position which amplifies the idea that there are good elements in this established method of traditional African science that can serve as complimentary to modern science (AKPAN 2010, 18).

Nevertheless, one of the challenges that traditional African science faces, according to Akpan, is the lack of an "attitude of free enquiry and openness of mind to criticism" (AKPAN 2010, 19). Akpan's claim is that the traditional African scientist has not moved beyond the level of personalization and esotericization of knowledge. This claim also concerns the inability of the traditional African scientists to rationally explain their phenomena and show how they arrive at their scientific conclusions. These are claims which connote that the method that the traditional African scientists employ is shrouded in secrecy to the extent that their knowledge of science is not displayed in the public sphere.

Granted that what all scientists do (including the traditional African scientists) is to advance new ways to think about the nature of science. Scientists research about the nature of cosmology and whether the world is deterministic. They consider the differences between what is certain and probability is. They also research further on the meaning of quantum mechanics, and medically about the wellbeing of society. No doubt, all such endeavors may require that one is involved in personalization or impersonalization of knowledge. This can be buttressed by the fact that what personalization of knowledge in science is, refers to the label that science is simply just what a scientist does. Science here refers to the sum of what individual scientists do. This was a fundamental feature of Western science during what could be referred to as the "heroic period in science. This was the period of "eponymy" as a prize in science. It was the period which recognized that what science really is, is just what the scientist does who discovers some eponymous law or effect or anomaly or reaction. So the personalization of knowledge in traditional African science also suggests that the great amount of knowledge that the individual scientist acquires would be for their individual glory (if there is a prize of eponymy to be giving), as well as for the benefit of society. Besides, it is wrong to assume that all traditional African scientists are involve in personalization of knowledge, as much as it is wrong to assume that western science can rationally or justifiable explain all Nphenomena. Isaac Newton's inability to explain what he called "action-at-distance", $\underset{\sigma}{0}$ classical physics is a case in point.

$\approx \quad$ On the issue of putting knowledge to public scrutiny and criticism, it is pertinent to note that as much as every element of human thinking should be open to 
potential criticism as Popper believed, one should be wary of criticisms that could pose a potential threat to the furthering of knowledge. Let it be clear that I agree with Popper that one should dispatch a formerly received way of thinking or invent a bold new form of theoretical thought. Popper, however, professed the need to be cautious in action. Ambitions that are utopian or revolutionary seemed to Popper always unacceptable. We must always be open to reforming our practices, but we must attempt this slowly and piecemeal. Every change that we make we must hold open to criticism. It should always remain possible for us to judge that some past reform of ours was a misstep (POPPER 1945, 122). So, on the criticism that the method of traditional African science is usually not made open for public scrutiny, it can be argued that outcomes of technical knowledge with inherent commercial values, both for the individual scientist and for the good of society, often require certain level of caution. This may be necessary against bastardisation and distortion of the core elements of the knowledge concern. As such it may require a certain level of technical and educational expertise or some legal backing for the knowledge to be made open. This is also a practice in Western science with what is known as "protective attitude of knowledge" as can be found in the idea of patency.

Following the above, the expectation that traditional African science should take a cue from the Western science method of "rigorous theorization which results in impersonalization, esotericization and non-veneration of inexplicable authorities" (AKPAN 2010, 20), is misplaced. The inevitability of metaphysics, and perhaps the ontological relevance of the principle of causality in science must be re-emphasized. What characterizes traditional African science method is the embrace of both empirical and non-empirical procedures of knowledge. This case is strong, and I rehearse the argument that there are perhaps some finitude which are difficult to be proved by mere observational or experimental procedures, yet we believe tenaciously that they exist (UDUMA 1996, 115). In some cases, mere observation or even empirical experimentation of hypothesis does not give us the full knowledge of the physical universe; there are instances where we have to employ some extra empirical categories in interpreting what is given to us by our sense data (UDUMA 1996, 115). A fascinating example for this is the way some patients are often advised in formal hospitals to seek extra- empirical categories in the diagnosis of their ailments when X-rays, laboratory tests and MMR scans fail to detect or determine the nature of such ailments. Many of such cases abound, and testimonials are verifiable. Successful employments of non-empirical means to diagnose patients which are able to determine the nature of the ailments have also been recorded in the annals of traditional African science.

The non-empirical causal method of traditional African science is no doubt metaphysical, and can also be mystic, religious and in fact magical, as defended by NEmedolu in "From Magic to African Experimental science: Toward A New @Paradigm". Emedolu's thesis is that a magical tradition existed while experimental

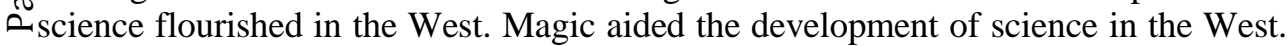
It is therefore not out of place when the method of African science is said to be laden 
with "spiritism and religious mythological entities that must be engaged through invocation" (EMEDOLU 2015, 80). So granted that what African science engages with are the "three different entities in the universe, such entities as matter, antimatter and non-matter" (CHIMAKONAM 2012a, 35), African science is by no means devoid of rigorous process. There are mechanisms for peer review among practitioners in such a way that regulate their practices, as well as the way it helps in knowledge sharing among themselves. There are also some elements of mentorship, which most often is knowledge taught to their offspring or outsiders who are willing to learn. The importance that governments in sub-Saharan Africa region now place on traditional medicine is indicative that the method(s) of traditional African science is acceptable as a complement to modern Western medicine of the formal setting. There have also been calls for the inclusion of African science into the school curriculum of some Western educational institutions as presented by Brian Murfin.

\section{Relevant Literature}

1. AFISI, Oseni. "The value of Cross-Cultural Polylogue in Science," [European Scientific Journal], pp103-115, October 2012. Vol. 8. No. 23. Paperback

2. __ "Karl Popper's Critical Rationalism: Corroboration versus Confirmation," [Philosophy Study], pp506-516, June 2013. Vol. 3. No. 6. Paperback

3. ___ "Conflicts between Science and Religion: The Popperian Critical Rationalist Resolution," [LASU Journal of Religions and Peace Studies], pp60-68, June 2016. Vol. 2. No.1._Paperback

4. AKPAN, Chris. "The method of African science: A philosophical evaluation" [American Journal of Social and Management Sciences], Vol. 2. No.1. 2010, pp11-20. http://www.scihub.org/AJSMS Paperback

5. BAJAH, Sam. "African Science: Fact or Fiction A Multidimensional Approach with Bias Towards Science Education. Intellectual Life" [Committee Monograph Number One], 1980. Dominguez Hills: California State University. Paperback 
6. BARTLEY, William W. III. "Theories of Demarcation between Science and Metaphysics," [Problems in the Philosophy of Science, I. LAKATOS and A. MUSGRAVE Eds.], 1968. North-Holland: Amsterdam. pp 40-64. Paperback

7. __ "Reply to Karl Popper," [Problems in the Philosophy of Science, I. LAKATOS and A. MUSGRAVE Eds.], 1968B. North-Holland: Amsterdam, pp113-119. Paperback

8. CHIMAKONAM, O. Jonathan. "Towards a Theory of African Science: Methods and Justification", [IOSR Journal of Pharmacy and Biological Sciences], Vol. 3. No 1, pp 33-41, 2012a. Web

9. ___ [Introducing African Science: Systematic and Philosophical Approach], 2012b. Authorhouse: Bloomington.Web

10. ___. "Introduction", [Atuolu Omalu: Some Unanswered Questions in Contemporary African Philosophy, edited by Jonathan O. Chimakonam], 2015. pp. 1-7. University Press of America: Lanham, Paperback.

11. "Conversational Philosophy as a New School of Thought in African Philosophy: A Conversation with Bruce Janz on the concept of "Philosophical Space", [Confluence: Journal of World Philosophies], Vol. 3. 2015. PP. 9-40. Paperback

12. "Transforming the African philosophical place through conversations: An inquiry into the Global Expansion of Thought (GET)", [South African Journal of Philosophy], Vol. 34. No 4. 2015, pp. 462-479. Paperback

13. EDET, Mesembe. I. "The Limitations of Bernard Matolino's "Limited Communitarianism": Continuing the Conversations on Personhood in African Philosophy", [Filosofia Theoretica: Journal of African Philosophy, Culture and Religions], Vol. 4. No.2. 2015. pp 100-111. Paperback

14. EMEDOLU, Christian. "From Magic to African Experimental science: Toward A New Paradigm", [Filosofia Theoretica: Journal of African Philosophy, Culture and Religions], Vol. 4. No.2. 2015. pp 68-88. Paperback

15. EZEABASILI, Nwankwo. [African Science Myth or Reality], 1977. Vantage Press: New York. Paperback

16. FEYERABEND, Paul. [Against Method], 1988. Verso of New Left Books: New York. Paperback 
17. GYEKYE, Kwame. "Philosophy, Culture and Technology in the PostColonial,', [Post-Colonial African Philosophy: A Critical Reader, E.C. EZE Ed.], 1997. Blackwell: Oxford. pp 25-44. Paperback

18. HUME, David. [Inquiries concerning Human Understanding and concerning the Principles of Morals], 1902. Clarendon Press: Oxford. Paperback

19. KUHN, Thomas. [The Structure of Scientific Revolutions], 1962. University of Chicago Press: Chicago. Paperback

20. MURFIN, Brian. "African Science, African and African-American Scientists and the School Science Curriculum," March 26-29, 1992. Paper Presented at the NSTA National Convention, Boston, Massachusetts.

21. NWEKE, Victor. C. A. "David Oyedola and the Imperative to Disambiguate the term "African Philosopher": A Conversation from the standpoint of The Conversational School of Philosophy (CSP)", [Filosofia Theoretica: Journal of African Philosophy, Culture and Religions], Vol. 4. No.2. 2015. Pp. 9499. Paperback

22. POPPER, Karl. [The Open Society and Its Enemies: The High Tide of Prophesy: Hegel, Marx, and the Aftermath], 1945. Routledge and Kegan Paul: London. Paperback

23. [The Logic of Scientific Discovery], 1959. Routledge: London and New York. Paperback

24. . [Conjectures and Refutations: The Growth of Scientific Knowledge], 1963. Routledge: London. Paperback

25. "Remarks on the Problems of Demarcation and of Rationality," [Problems in the Philosophy of Science, I. LAKATOS and A. MUSGRAVE Eds.], 1968B. North-Holland: Amsterdam. pp 88-102 Paperback

26. SUPPES, Patrick. "From Theory to Experiment and Back Again", [Observation and experiment in the Natural and Social Sciences, M.C. GALAVOTTI Ed.], 2003. Kluwer Academic Publishers: New York. pp 141. Paperback

27. UDUMA, Uduma. "Hume's Rejection of Metaphysics," [Metaphysics, Phenomenology and African Philosophy, J. UNAH Ed.], 1996. Fadec Publishers: Lagos. pp 93-121. Paperback 
Filosofia Theoretica: Journal of African Philosophy, Culture and Religions

28. UNAH, Jim. “'Ontologico - Epistemological Background to Authentic African Socio-economic and Political Institutions," [Footmarks on African Philosophy, A. F. UDUIGWOMEN Ed.], 1995. Obaroh and Ogbinaka Publishers: Lagos. pp107 - 123. Paperback

29. VAN SERTIMA, Ivan. (Ed). [Blacks in Science: Ancient and Modern]. 1984. Transaction Books: New Brunswick. Paperback

30. VICKERS, John. "The Problem of Induction," [The Stanford Encyclopaedia of Philosophy, E. N. Zalta Ed.], spring 2013. Web. Retrieved, March, 23, 2016. http://plato.stanford.edu/archives/spr2013/entries/induction-problemg

31. WILSON, Edward. [Consilience: The unity of knowledge], 1998. Knopf: New York. Paperback 